\title{
Incidence, Predictive Factors and Prognosis of Tuberculosis among Patients with HIV Infection in Guadeloupe 1988-2009
}

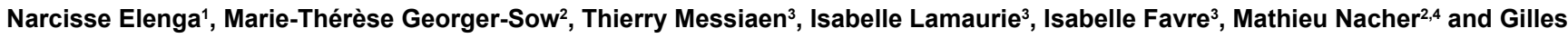
Beaucaire $^{3}$

${ }^{1}$ Service de Pédiatrie, Centre Hospitalier de Cayenne, Andrée Rosemon, Rue des Flamboyants, BP 6006-97306 Cayenne Cedex, Guyane Française ${ }^{2}$ Coordination Régionale VIH (COREVIH) Guadeloupe CHU de Pointe-à-Pitre / Abymes Bâtiment B Ancien Hôpital Ricou 2ème étage BP 46597159 Pointe-à-Pitre Cedex, Guyane Française

${ }^{3}$ Service des maladies infectieuses, Guadeloupe CHU de Pointe-à-Pitre / Abymes Bâtiment B Ancien Hôpital Ricou 2ème étage BP465 97159, Pointe-à-Pitre Cedex, Guyane Française

${ }^{4}$ Centre d'Investigation Clinique Epédémiologie Clinique CIC EC Antilles Guyane CIE 802, Centre Hospitalier de Cayenne, Andrée Rosemon, Rue des Flamboyants, BP 6006-97306 Cayenne Cedex, Guyane Française

\author{
Abstract \\ Objective: To determine the incidence, risk factors and prognosis for incident tuberculosis during the follow-up of \\ HIV-infected patients in Guadeloupe.
}

Methods: We conducted a retrospective cohort study using STATA version IC 10.0 (College Station, Texas, USA).

Results: A single failure Cox proportional hazards model showed that patients with $B C D C$ category $(H R=4.50$; $95 \% \mathrm{Cl}=1.50-13.60 ; \mathrm{P}=0.007)$ and patients with $\mathrm{C} C D C$ category $(\mathrm{HR}=138.30 ; 95 \% \mathrm{Cl}=62.80-304.90 ; \mathrm{P}=0.000)$ were at an increased risk of tuberculosis, whereas patients with low median $\mathrm{CD} 4$ count at enrolment $(\mathrm{HR}=0.50 ; 95 \% \mathrm{Cl}=0.30$ $0.84 ; \mathrm{P}=0.009)$ and patients treated by ART ( $\mathrm{HR}=0.45 ; 95 \% \mathrm{Cl}=0.34-0.62 ; \mathrm{P}=0.000)$ were associated with a low risk of tuberculosis.

Conclusion: Our data showed a high incidence of tuberculosis and no socio-economic factors related to tuberculosis among HIV-infected patients. These findings help to effectively guide public health interventions.

Keywords: HIV-infected patients; Tuberculosis; Incidence; Predictive factors; Prognosis; Guadeloupe

\section{Introduction}

Tuberculosis (TB) continues to be an important global public health problem, intensified by the human immunodeficiency virus (HIV) epidemic. In 2010, there were 8.8 million (range, 8.5-9.2 million) incident cases of tuberculosis, 1.1 million (range, 0.9-1.2 million) deaths from TB among HIV-negative people and an additional 0.35 million (range, 0.32-0.39 million) deaths from HIV-associated TB [1]. The HIV/AIDS pandemic is responsible for the resurgence of TB worldwide, resulting in increased morbidity and mortality. HIV and Mycobacterium tuberculosis have a synergistic interaction; each propagates progression of the other.

In Guadeloupe, tuberculosis affecting the migrant population was characterised by the young age of the patients and a significant proportion of co-infection by the human immunodeficiency virus. However, HIV infection increased the risk of developing severe tuberculosis [2].

These French overseas territories are characterized by an important immigration from countries with high TB incidence and high HIV prevalence [3,4]. French Guiana and Guadeloupe have significant immigration from Haiti where TB is prevalent [5], and TB incidence in the island of Guadeloupe is much lower than in continental French Guiana or even in metropolitan France. Genotyping studies [6] in the overseas French territories have calculated that recent infections are much more frequent in French Guiana (49.3\%) than in Guadeloupe (27.2\%) and that TB cases in foreign patients were of diverse South American sources in French Guiana whereas they mostly were from Haiti in Guadeloupe [6]. Although there are a lot of migrations in the Caribbean, and tuberculosis is frequent in Caribbean countries, tuberculosis was the $5^{\text {th }}$ cause of AIDS in Guadeloupe, the $4^{\text {th }}$ in French
Guiana, whereas it was the number 1 cause of AIDS in metropolitan France. The more rural setting in the overseas French territories and the importance of migrations from sub-Saharan Africa in metropolitan France may explain this difference [7].

The study objective was to determine the incidence, risk factors and prognosis for incident TB during the follow-up of HIV-infected patients in Guadeloupe.

\section{Background}

Guadeloupe (French West Indies) is an overseas French department, which has a large number of persons living with HIV/AIDS. A large part of these are foreign females, mainly native to Haiti. The standards of healthcare in Guadeloupe are similar to those of metropolitan France. All human immunodeficiency virus (HIV) patients receive free antiretroviral treatments (including the most recent drugs) regardless of their origin or socioeconomic level. Radiology, viral loads, CD4 counts and genotyping, and antiretroviral concentration measurements are available for routine care. There is a reference university hospital with laboratories that specialise in parasitology, mycology and bacteriology

*Corresponding author: Narcisse Elenga, Service de Pédiatrie, Centre Hospitalie de Cayenne, Andrée Rosemon, Rue des Flamboyants, BP 6006-97306 Cayenne Cedex, Guyane Française, Tel: +594 694978 048; Fax: +594 594 394819; E-mail: elengafr@yahoo.fr

Received June 28, 2013; Accepted August 26, 2013; Published August 30, 2013

Citation: Elenga N, Georger-Sow M-T, Messiaen T, Lamaury I, Favre I, et al. (2013) Incidence, Predictive Factors and Prognosis of Tuberculosis among Patients with HIV Infection in Guadeloupe 1988-2009. J AIDS Clin Res 4: 235. doi: 10.4172/2155 6113.1000235

Copyright: (C) 2013 Elenga N, et al. This is an open-access article distributed under the terms of the Creative Commons Attribution License, which permits unrestricted use, distribution, and reproduction in any medium, provided the original author and source are credited. 
as well as the Pasteur Institute for the diagnosis of tuberculosis (Pasteur Institute of Guadeloupe and Pasteur Institute of French Guiana).

\section{Patients and Methods}

\section{Study population and sources of information}

The HIV-positive patients followed in the University hospital of Pointe-à-Pitre, and Basse Terre hospital since January $1^{\text {st }} 1988$ and St Martin Hospital since January $1^{\text {st }} 1992$ until 31 December 2009 were enrolled in the Guadeloupe section of French Hospital Database for HIV (GFHDH). The French Hospital Database for HIV (FHDH) is a large prospective cohort study of HIV-infected patients who are aged $>15$ years and have been treated in a network of 68 French university hospitals. The enrollment criteria are documented HIV-1 or HIV-2 infection and written informed consent. Trained research assistants use French Ministry of Health DMI2 software to collect and record, on standardized forms, clinical and biological data at the time of study inclusion and at each visit or hospital admission for an HIV-related clinical event or a new treatment prescription or at least every 6 months. Diagnoses are coded according to the 10th International Classification of Diseases [8]. All patients (newly diagnosed and known HIV patients) followed between 1997 and 2009 were included.

Time-independent variables such as sex, nationality and transmission routes, and time-dependent variables such as age, weight, clinical events and therapeutic data, HIV-1 viral loads, CD4 and CD8 counts are routinely entered in the database by trained Clinical Studies Technicians. Patients included in the GFHDH have given informed consent to the use of their data. Their identity is encrypted before the data are sent to the Ministry of Health and the Institut National de la Recherche Médicale (INSERM) which centralize data from Regional Coordination of the Fight against HIV (COREVIH) throughout France. This data collection is approved by the Commission Nationale Informatique et Libertés (CNIL), a national committee that oversees research data, in order to protect patients personal data. The data were analysed with STATA 10.0 (Stata Corp LP, College Station, TX, USA). We calculated the incidence rate of tuberculosis in the HIV-infected individuals that were followed-up in clinical centres in Guadeloupe between 1988 and 2009, using survival times (st) functions in Stata.

In addition, general characteristics of AIDS patients in Guadeloupe, Metropolitan France and French Guiana were compared using data from the mandatory AIDS reporting system available on the Institut National de Veille Sanitaire (INVS) [9].

The patient characteristics in the Guadeloupe FHDH at the time of AIDS were also studied numbers, sex, age, CD4 count and antiretroviral treatment at the time of diagnosis, and Knowledge of a positive HIV test within the 15 days of the TB diagnosis.

\section{Definition of tuberculosis cases}

All TB events (pulmonary or extra-pulmonary) were reported in the database.

A confirmed pulmonary TB case had to include two of the following three criteria

- Fever, dyspnoea, cough, weight loss or fatigue,

- Positive AFB smear on 2 or more sputa,

- Culture or PCR positive for M. tuberculosis from sputum or bronchial lavage or lung tissue. criteria

A probable case of pulmonary TB had to meet the following four
- Fever, dyspnoea, cough, weight loss or fatigue,

- Abnormal chest X-ray,

- Acid-fast bacillus (AFB) seen in sputum or lavage or lung tissue but not grown in culture,

- Response to anti-tuberculous treatment.

- A confirmed case of extra-pulmonary TB was defined by both of the following criteria:

- Compatible symptoms,

- Culture or PCR from blood or affected tissue.

- A probable case of extra-pulmonary TB was defined as:

- Compatible symptoms, plus either,

- $\quad$ AFB seen in affected tissue or blood,

- Concurrent diagnosis of pulmonary TB,

- or responds to treatment.

\section{Statistical methods}

TB incidence rates were calculated per 100 person years at risk (py). Patients were censored at the time of TB diagnosis or at the date of death or date of last visit in cases lost to follow-up. The factors associated with tuberculosis were analysed using a Cox model. Bivariate analysis first studied covariates and their relation to the outcome measure using a crude hazard ratio (HR) and its confidence interval. The covariates that were associated with the outcome $(\mathrm{p}<0.2)$ were then included in a multivariate Cox model yielding adjusted hazard ratios. For all tests performed, a p value of 0.05 or less was considered as statistically significant. The selection of the most parsimonious model was performed using the Akaike information criteria (AIC) by keeping the model with the lowest AIC value. The data were analysed with STATA 10.0 (Stata Corp LP, College Station, TX, USA).

\section{Results}

Among the 2,739 patients enrolled in the Guadeloupe section of the French Hospital Database on HIV infection in the study period, 235 cases of tuberculosis (77 females and 158 males) were noted (8.6\%), with a total of 8909 person-years of follow-up. The global incidence rate of tuberculosis was 2.8 per 100 person-years (CI 95\% 2.4-3.1 py). This incidence decreased from the period 1988-1996 to the period 2001-2004, then remained high in the period 2005-2009. In Figure 1,

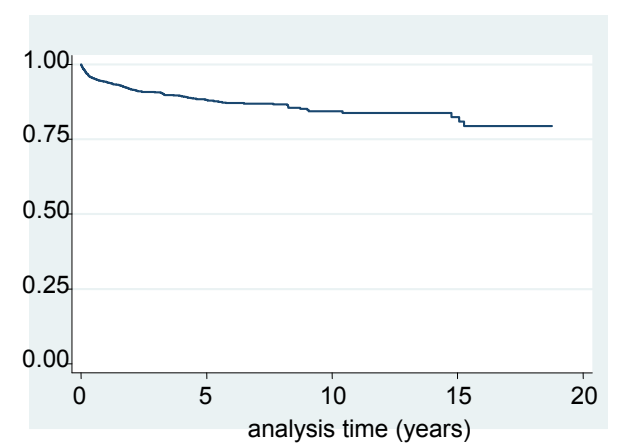

Figure 1: Kaplan-Meier estimates representing the survival function with tuberculosis as failure event, over time"1988-2009 hospital cohort in Guadeloupe ( $n=2739)$ ". 


\begin{tabular}{|c|c|c|c|c|c|}
\hline Variables & Time at risk (years) & Tuberculosis ( $n$ ) & Crude incidence rate per 100 py & Adjusted hazard ratio* $(95 \% \mathrm{Cl})$ & $\mathrm{P}$ \\
\hline \multicolumn{6}{|l|}{ Age } \\
\hline$\leq 40$ & 6050.14 & 136 & 1.9 & & \\
\hline$>40$ & 2858.89 & 99 & 4.2 & - & - \\
\hline \multicolumn{6}{|l|}{ Gender } \\
\hline Female & 3676.3 & 77 & 1.9 & & \\
\hline Male & 5032.7 & 158 & 3.1 & - & - \\
\hline \multicolumn{6}{|c|}{ HIV diagnosis period } \\
\hline 2005-2009 & 481.6 & 21 & 4.4 & & \\
\hline 2001-2004 & 1790.8 & 25 & 1.4 & - & - \\
\hline $1997-2000$ & 3077.8 & 74 & 2.4 & $0.46(0.20-1.05)$ & 0.065 \\
\hline 1988-1996 & 3558.8 & 115 & 3.2 & $0.80(0.37-1.73)$ & 0.57 \\
\hline \multicolumn{6}{|l|}{ CD4 cell count } \\
\hline$>500$ & 2323.9 & 19 & 0.8 & 1 & \\
\hline $200-500$ & 2887.4 & 64 & 2.2 & $0.80(0.48-1.34)$ & 0.40 \\
\hline$<200$ & 2122.8 & 109 & 5.1 & $0.50(0.30-0.84)$ & 0.009 \\
\hline \multicolumn{6}{|l|}{ CDC categories } \\
\hline$A$ & 5113.7 & 47 & 0.9 & 1 & \\
\hline B & 1754.8 & 29 & 1.7 & $4.50(1.50-13.60)$ & 0.007 \\
\hline C & 2040.6 & 159 & 7.8 & 138.30(62.80-304.90) & 0.000 \\
\hline \multicolumn{6}{|l|}{ ARTherapy } \\
\hline No & 4399.40 & 132 & 3.1 & 1 & \\
\hline Yes & 4509.04 & 103 & 2.4 & $0.45(0.34-0.62)$ & 0.000 \\
\hline
\end{tabular}

*Obtained using a Cox proportional hazard model including all the above variables and tuberculosis as the failure event.

Cl: confidence interval; py: person-years.

Table 1: Predictive factors of tuberculosis among patients with HIV infection in Guadeloupe: 1988-2009.

the Kaplan-Meier estimates representing the survival function with tuberculosis as failure event, over time. Of the tuberculosis cases, 109 patients had a CD4 cell count below $200 / \mathrm{mm}^{3}$. Mean age was $35.6 \pm 0.4$ years. There were 6 deaths recorded (2.6\%): 4 pulmonary tuberculosis with cavity in Chest $\mathrm{x}$-ray and 2 disseminated tuberculosis. Table 1 shows the incidence rates of tuberculosis and the adjusted hazard ratios for various factors. A single failure Cox proportional hazards model showed that patients, with B CDC category $(\mathrm{HR}=4.50 ; 95 \% \mathrm{CI}=1.50$ 14.60; $\mathrm{P}=0.007)$ and patients with $\mathrm{C} C \mathrm{CDC}$ category $(\mathrm{HR}=138.30 ; 95 \%$ $\mathrm{CI}=62.80-304.90 ; \mathrm{P}=0.000)$ were at an increased risk of tuberculosis. On the other hand, low CD4 count at enrolment $(\mathrm{HR}=0.50 ; 95 \%$ $\mathrm{CI}=0.30-0.84 ; \mathrm{P}=0.009)$ and the antiretroviral therapy $(\mathrm{HR}=0.45 ; 95 \%$ $\mathrm{CI}=0.34-0.62 ; \mathrm{P}=0.000)$ were associated with a low risk of tuberculosis.

\section{Discussion}

In this population-based retrospective cohort analysis of adult HIV-infected patients, we observed a high incidence of TB. The high incidence of TB in our cohort patients suggests the importance of the early initiation of ART. Indeed, antiretroviral therapy (ART) has beneficial effects on mortality and lowers the risk of developing TB by $70-90 \%$ [8-11]. In our study, patients with CD4 count $<200 / \mathrm{mm} 3$ were usually put under ART in order to improve their immune status and to prevent tuberculosis and any other opportunistic infection in these patients. That is why they where in low risk of tuberculosis. However, TB occurred in young patients (mean age $35.6 \pm 0.4$ years), which is similar to results found by other studies [2,12]. A higher proportion of our patients with TB had median baseline CD4+ T-lymphocyte counts $<200$ cells/mm [13] compared to patients without TB (62.9\% vs. $39.9 \%$, respectively, $\left.\mathbf{X}^{2}, \mathrm{p}=0.000\right)$. This suggests that those who developed TB may have been more immunocompromised at baseline than patients remaining TB free. TB-induced immunosuppression is a well-studied area: an investigation of $\mathrm{T}$ cell cytokine responses in HIV-negative pulmonary TB patients showed a persistent depressed tuberculininduced IFN- $\gamma$ response up to 18 months despite successful treatment, suggesting a long-lasting depletion or primary dysfunction of antigenresponsive T cells from the peripheral blood due to active TB [9]. Our results shown that the incidence of tuberculosis decreased from the period 1988-1996 to the period 2001-2004. Brudey et al. [14] reported that the incidence of tuberculosis decreased between 1994 and 2000 in the Guadeloupian general population. However, patients with advanced CDC category were at increased risk of tuberculosis. The patients who developed TB disease in our study had similar risk factors for TB in HIV-infected patients than other settings [11,13-18]. According to one author, the risk of tuberculosis increases with the duration of HIV infection [19]. Our study had several limitations. First, although most of our results are consistent with previous studies, some potential risk factors, such as education, HIV knowledge and awareness, religion affiliations, and employment status, were not recorded. Due to the retrospective and observational design of this study, we were also unable to study the risk factors of TB-associated "immune reconstitution inflammatory syndrome" (IRIS), which occurs in HIV/AIDS patients who recently started highly active antiretroviral treatment (HAART). Indeed, many recent studies have reported an increased incidence of TB-associated IRIS [19-30]. According to the International Network for the Study of HIV-Associated IRIS (INSHI), ART-associated TB refers to all TB diagnosed during ART, while the subset of patients who develop rapidly progressive signs and symptoms of TB, with exuberant inflammatory features, after the initiation of ART are called 
Citation: Elenga N, Georger-Sow M-T, Messiaen T, Lamaury I, Favre I, et al. (2013) Incidence, Predictive Factors and Prognosis of Tuberculosis among Patients with HIV Infection in Guadeloupe 1988-2009. J AIDS Clin Res 4: 235. doi: 10.4172/2155-6113.1000235

"unmasking TB-associated IRIS" [30]. The increased incidence of TB in the period 2005-2009 could be due to the increased number of cases of TB-IRIS. Clinicians should remain highly vigilant in HIV patients who develop TB after starting ART, as they can have much more severe disease, can deteriorate rapidly due to immune reconstitution, and may even require hospitalisation. Early ART initiation and intensified TB screening upon ART initiation are crucial to reduce incident TB.

In the present study, no statistically significant influence of age, gender or HIV diagnosis period was found, in contrast to the findings of previous studies [15,17-19].

Despite the limitations of the study, the high incidence of tuberculosis, its prognosis and its predictors in the Guadeloupian HIVpatients cohort helps to better understand the HIV/AIDS epidemic and effectively guide public health interventions. Our findings, however, are applicable to patients from other Overseas French Departments and the Caribbean areas.

\section{Conclusion}

TB incidence rates during the period 2001-2004 remained substantially lower than rates in the period 2005-2009. The duration of the disease, its advanced stage with profound immunosuppression, and the late initiation of ART are the predictive factors of tuberculosis in HIV-infected patients. Early ART initiation and intensified TB screening at ART initiation are crucial to reduce incident TB.

\section{References}

1. WHO (2012) Global tuberculosis report 2012.

2. Cadelis G, Rossigneux E, Millet J, Rastogi N (2012) [Comparative epidemiological study of the tuberculosis - migrant and native subjects in Guadeloupe from 2006 to 2011]. Rev Mal Respir 29: 858-870.

3. Filliol I, Ferdinand S, Sola C, Thonnon J, Rastogi N (2002) Spoligotyping and IS6110-RFLP typing of Mycobacterium tuberculosis from French Guiana: a comparison of results with international databases underlines interregional transmission from neighboring countries. Res Microbiol 153: 81-88.

4. Rastogi N, Schlegel L, Pfaff $F$ (1998) La tuberculose dans la région AntillesGuyane: situation épidémiologique de 1994 à 1996. Bull Epidemiol Hebdo 11: 45-47.

5. Deschamps MM, Fitzgerald DW, Pape JW, Johnson WD Jr (2000) HIV infection in Haiti: natural history and disease progression. AIDS 14: 2515-2521.

6. Brudey K, Filliol I, Ferdinand S, Guernier V, Duval P, et al. (2006) Long-term population-based genotyping study of Mycobacterium tuberculosis complex isolates in the French departments of the Americas. J Clin Microbiol 44: 183191.

7. Elenga N, Georger-Sow MT, Messiaen T What is AIDS in Guadeloupe? A descriptive and comparative study. In press

8. World Health Organization (1993) International Classification of Diseases. 10th Revision (ICD-10). WHO, Geneva.

9. Brudey K, Filliol I, Théodore M, Sola C, Rastogi N (2006) [Molecular epidemiology of tuberculosis in Guadeloupe from 1994 to 2000]. Pathol Biol (Paris) 54: 14-21.

10. Girardi E, Antonucci G, Vanacore P, Palmieri F, Matteelli A, et al. (2004) Tuberculosis in HIV-infected persons in the context of wide availability of highly active antiretroviral therapy. Eur Respir J 24: 11-17.

11. Jones JL, Hanson DL, Dworkin MS, DeCock KM, Adult/Adolescent Spectrum of HIV Disease Group (2000) HIV-associated tuberculosis in the era of highly active antiretroviral therapy. The Adult/Adolescent Spectrum of HIV Disease Group. Int J Tuberc Lung Dis 4: 1026-1031.

12. Lawn SD, Badri M, Wood R (2005) Tuberculosis among HIV-infected patients receiving HAART: long term incidence and risk factors in a South African cohort. AIDS 19: 2109-2116.

13. Hermans SM, Kiragga AN, Schaefer P, Kambugu A, Hoepelman Al, et al. (2010)
Incident tuberculosis during antiretroviral therapy contributes to suboptimal immune reconstitution in a large urban HIV clinic in sub-Saharan Africa. PLoS One 5: e10527.

14. Hirsch CS, Toossi Z, Othieno C, Johnson JL, Schwander SK, et al. (1999) Depressed T-cell interferon-gamma responses in pulmonary tuberculosis: analysis of underlying mechanisms and modulation with therapy. J Infect Dis 180: 2069-2073.

15. Bleed D, Dye C, Raviglione MC (2000) Dynamics and control of the global tuberculosis epidemic. Curr Opin Pulm Med 6: 174-179.

16. Raviglione MC, Harries AD, Msiska R, Wilkinson D, Nunn P (1997) Tuberculosis and HIV: current status in Africa. AIDS 11 Suppl B: S115-123.

17. Selwyn PA, Hartel D, Lewis VA, Schoenbaum EE, Vermund SH, et al. (1989) A prospective study of the risk of tuberculosis among intravenous drug users with human immunodeficiency virus infection. N Engl J Med 320: 545-550.

18. Badri M, Ehrlich R, Pulerwitz T, Wood R, Maartens G (2002) Tuberculosis should not be considered an AIDS-defining illness in areas with a high tuberculosis prevalence. Int J Tuberc Lung Dis 6: 231-237.

19. van Asten L, Langendam M, Zangerle R, Hernández Aguado I, Boufassa F, et al (2003) Tuberculosis risk varies with the duration of HIV infection: a prospective study of European drug users with known date of HIV seroconversion. AIDS 17: $1201-1208$.

20. Wendel KA, Alwood KS, Gachuhi R, Chaisson RE, Bishai WR, et al. (2001) Paradoxical worsening of tuberculosis in HIV-infected persons. Chest 120: 193197.

21. Navas E, Martín-Dávila P, Moreno L, Pintado V, Casado JL, et al. (2002) Paradoxical reactions of tuberculosis in patients with the acquired immunodeficiency syndrome who are treated with highly active antiretroviral therapy. Arch Intern Med 162: 97-99.

22. Breton G, Duval X, Estellat C, Poaletti X, Bonnet D, et al. (2004) Determinants of immune reconstitution inflammatory syndrome in HIV type 1-infected patients with tuberculosis after initiation of antiretroviral therapy. Clin Infect Dis 39: 1709-1712.

23. Kumarasamy N, Chaguturu S, Mayer KH, Solomon S, Yepthomi HT, et al (2004) Incidence of immune reconstitution syndrome in HIV/tuberculosiscoinfected patients after initiation of generic antiretroviral therapy in India. J Acquir Immune Defic Syndr 37: 1574-1576.

24. Michailidis C, Pozniak AL, Mandalia S, Basnayake S, Nelson MR, et al. (2005) Clinical characteristics of IRIS syndrome in patients with HIV and tuberculosis. Antivir Ther 10: 417-422.

25. Bourgarit A, Carcelain G, Martinez V, Lascoux C, Delcey V, et al. (2006) Explosion of tuberculin-specific Th1-responses induces immune restoration syndrome in tuberculosis and HIV co-infected patients. AIDS 20: F1-7.

26. Manosuthi W, Kiertiburanakul S, Phoorisri T, Sungkanuparph S (2006) Immune reconstitution inflammatory syndrome of tuberculosis among HIV-infected patients receiving antituberculous and antiretroviral therapy. J Infect 53: 357363.

27. Lawn SD, Myer L, Bekker LG, Wood R (2007) Tuberculosis-associated immune reconstitution disease: incidence, risk factors and impact in an antiretroviral treatment service in South Africa. AIDS 21: 335-341.

28. Park WB, Choe PG, Jo JH, Kim SH, Bang JH, et al. (2007) Tuberculosis manifested by immune reconstitution inflammatory syndrome during HAART. AIDS 21: 875-877.

29. Serra FC, Hadad D, Orofino RL, Marinho F, Lourenço C, et al. (2007) Immune reconstitution syndrome in patients treated for HIV and tuberculosis in Rio de Janeiro. Braz J Infect Dis 11: 462-465.

30. Meintjes G, Lawn SD, Scano F, Maartens G, French MA, et al. (2008) Tuberculosis-associated immune reconstitution inflammatory syndrome: case definitions for use in resource-limited settings. Lancet Infect Dis 8: 516-523. 